\title{
Developing a Robust Strategy Map in Balanced Scorecard Model Using Scenario Planning
}

\author{
Mostafa Jafari, Kamran Shahanaghi, and Majid Tootooni \\ Department of Industrial Engineering, Iran University of Science \& Technology, Tehran 16846-13114, Iran \\ Correspondence should be addressed to Majid Tootooni; m_tootooni@iust.ac.ir
}

Received 14 November 2014; Revised 22 February 2015; Accepted 27 February 2015

Academic Editor: Jianxiong Ye

Copyright ( 2015 Mostafa Jafari et al. This is an open access article distributed under the Creative Commons Attribution License, which permits unrestricted use, distribution, and reproduction in any medium, provided the original work is properly cited.

\begin{abstract}
The key to successful strategy implementation in an organization is for people in the organization to understand it, which requires the establishment of complicated but vital processes whereby the intangible assets are converted into tangible outputs. In this regard, a strategy map is a useful tool that helps execute this difficult task. However, such maps are typically developed based on ambiguous cause-effect relationships that result from the extrapolation of past data and flawed links with possible futures. However, if the strategy map is a mere reflection of the status quo but not future conditions and does not embrace real-world uncertainties, it will endanger the organization since it posits that the current situation will continue. In order to compensate for this deficiency, the environmental scenarios affecting an organization were identified in the present study. Then the strategy map was developed in the form of a scenario-based balanced scorecard. Besides, the effect of environmental changes on the components of the strategy map was investigated using the strategy maps illustrated over time together with the corresponding cash flow vectors. Subsequently, a method was proposed to calculate the degree of robustness of every component of the strategy map for the contingency of every scenario. Finally, the results were applied to a post office.
\end{abstract}

\section{Introduction}

Balanced scorecard (BSC) is a strong tool used in performance assessment by many successful organizations in the world. BSC converts organizational mission and strategies into goals and criteria that are categorized into four dimensions including learning and growth, internal business processes, customer, and financial aspects. Currently, BSC is the only management system that can incorporate strategies into performance and budget in order to answer the existing challenges. In a report published by Organization for Economic Co-operation and Development (OECD) in 2005 on performance assessment and management systems and operational budgeting in public organizations, it was noted that most of the public organizations tended to launch BSC management systems to establish performance management assessment systems.

Strategy map constitutes the foundation of BSC. According to Kaplan and Norton, successful implementation of BSC is based on the exact illustration of cause-effect relations among strategic goals of the organization in its different aspects. Strategy map is a tool that establishes connections among organizational strategies and among the processes and systems that contribute to strategy implementation. It provides the organization and its employees with a straightforward, transparent view so that they know how their jobs and activities would eventually adhere to the comprehensive organizational goals and coordinate their activities.

The burgeoning complexities and increasing changes in technology as well as the changing institutions and environment are the challenges that face businesses continuously. When managers are exposed to challenges of the business environment, their ability to make effective decisions is vital for organizational survival. Considering the measuring of strategic goals, there is often a misconception about the relationships among goals. This misconception lies in that there are uncertainties of the nature of a lack of knowledge about the strength of relations and interactions among components in BSC and strategy map. Since past performance data are used in developing strategy maps in BSC model, the possible future and prospective scenarios are ignored. 
The concept of robust strategy map is used in the present study in order to provide for the management of environmental uncertainties based on BSC model. Once environmental uncertainties are addressed in an organization and a strategy map is developed for it, the organization may be better prepared to deal with strategic uncertainties in the long run. In the present study, the environmental scenarios are identified first in order to obtain a robust, resilient strategy map in dealing with environmental uncertainties. Subsequently, net present value (NPV) technique is used to determine the value of every hyperpath on the strategy map in each scenario. Finally, the compatibility of every hyperpath is computed by considering all scenarios in terms of their contingencies. Then the optimal combination of hyperpath choices is determined by considering all scenarios.

This report is designed as follows: the second section reviews the literature on BSC-based performance assessment, strategy map, and scenario-based planning. Then the key theoretical concepts are elaborated on. The methodology and research framework are explained and illustrated schematically in the third section. The proposed methodology is implemented in Iran Post Company, and the obtained results are reported in the fourth section. The last section of this paper is designed to draw conclusions and recommend directions for future studies.

This paper is organized as follows. Section 2 reviews the relevant literature. Our methodology is developed in Section 3. Section 4 is dedicated to a case study in the Iranian Post Company and the numerical results. Finally, Section 5 concludes the paper.

\section{Literature Review}

2.1. Balanced Scorecard (BSC). BSC was introduced by Kaplan and Norton. It comprises four aspects of growth and learning, internal business processes, customer, and financial dimension. It is a strategic approach and organizational performance management system that can be used to implement perspectives and strategies. This model is considered as a transition from business-unit strategies to a set of relations among criteria, which provides a mechanism to achieve goal-related feedback along with long-term strategic goals. Strategy map is another strong tool introduced by Kaplan and Norton [1]. Organizations use strategy maps to explain the relations among intangible assets and value creation with great precision and transparency. In other words, strategy map is a tool to implement strategy and create a macropicture of the relationships among performance goals of the organization. The main deficiencies of BSC include a lack of time dimension between cause and effect in the strategy map, insufficient relationships among strategy, and operations and excessive concentration on the organizations' inside.

Although the development and utilization of strategy maps can bear advantages, some researchers emphasized their deficiencies $[2,3]$. An important concern is that reliance on the relational cause-effect model presented in the strategy map may not be sufficient to reflect the evolutionary trend of strategy over time [4]. Reliance on a static strategy map in the medium term and in the long run would entail the assumption that not only the organization and its strategy remain stable, but also the competitors continue their previous behavior. Besides, once it is assumed that strategy maps have predictability characteristics, a validation question is raised about how the analysis of past data can be a basis for the prediction of future situation.

First of all, strategy maps do not consider the potential time lag in relation to performance indicators. Second, future conditions will change so that the relations that were valid in the past may not be valid in future. Thus, the organization risks designing a map that focuses on the development of linear set of performance indicators irrespective of the potential changes in future [4].

2.2. Scenario Planning. As a useful tool, scenarios help organizations prepare for possible futures and make them more resilient and creative [5]. A scenario refers to the plot of a performance, a line of motion picture, or a TV broadcast [6]. Scenario planning is often used by managers to embody their subjective models for future in order to make better decisions [7]. Scenarios are used to predict the key factors in technology planning, forecast, strategic analysis, and futurology.

Systematic use of scenarios was started after World War II to clarify thinking about future. United States defense system used scenarios as a method of military planning in the $1950 \mathrm{~s}$ $[6,8-10]$. Afterwards, scenario methodology was extensively employed for social prediction, analysis of public policies, and decision-making in the 1960s. The process of scenario construction exerted a strong effect on thought and decisionmaking process and was considered as the harbinger of public debates [11].

Porter defined scenario as an internal display of what may happen in future, rather than a prediction but an output of possible future [12]. According to Schwartz, scenario analysis is a tool to organize peoples' understanding of future when their decision will be effective [13].

Scenarios can be used to prepare the organization for what may turn out in future. Scenario planning is a qualitative, systematic method to illustrate the possible conditions in future [14]. Using scenario planning, the involved individuals create coherent stories that develop based on the current trends and future perspectives outside the organization [15]. Schwartz contends that two or three scenarios are usually considered [13]. One scenario can be an extrapolation of the status quo (maintaining the current situation). The second can be a description of a bright future that will lead to favorable conditions because the organization is ready to embrace it. The third scenario can depict a pessimistic scenario (e.g., a fragmentation or discontinuity that causes failure due to a lack of organizational readiness).

When scenarios are created, managers can take measures to reduce the risks induced by major uncertainties using the identified opportunities and by keeping the risk within an acceptable limit [15].

2.3. Scenario Planning and Strategy Map. What is evident in most studies on strategy map is the intraorganizational tendency in designing the strategy map. Nevertheless, 
extraorganizational parameters that affect organizational performance are overlooked. When the strategy map is developed with an intraorganizational view, the organization will be less prepared to deal with environmental changes in future. Incorporating into the intraorganizational view the impact of possible futures and future trends affecting the organization would provide a comprehensive and favorable combination. Thus, a robust strategy map may be developed by combining the knowledge of environmental uncertainties outside the organization with performance-related intraorganizational knowledge in the BSC model.

As discussed, scenario planning technique is used to display extraorganizational knowledge. A list of potential scenarios affecting the organization can include the knowledge related to environmental uncertainties affecting the organization. The important point here is to combine scenario planning with the strategy map. Buytendijk et al. (2010) conducted a study on the scenario-based strategy map. They developed three scenarios for an organization and a distinctive strategy map for every scenario [16]. Then they compared the strategy maps corresponding to every scenario and determined the strategic goals among them. There were common goals in the strategy maps corresponding to every three scenarios, which they established in the final strategy map as strategic imperatives. Some goals were common in the strategy maps corresponding to two scenarios out of the three, which they maintained in the final strategy map as strategic choices. Finally, they eliminated the goals that existed only in the strategy map corresponding to a single scenario.

2.4. Fuzzy Inference System. Nowadays, researchers use many intelligent techniques such as fuzzy inference system (FIS) and adaptive neuro-fuzzy inference system (ANFIS) as effective tools for modeling engineering systems [17]. Fuzzy inference is considered as the process of mapping a set of input data to a set of output data, which is expressed using fuzzy logic approach. An FIS is a process that formulates human language into if-then rules using fuzzy logic. An FIS usually consists of four major parts including fuzzification, fuzzy rules, fuzzy inference engine, and defuzzification [18]. Scenario planning and strategic planning are cited in the literature as the areas where the above techniques are used.

Moayer et al. (2007) used ANFIS technique to create different scenarios and compensate for the deficiency of experts' linguistic data [19]. Yu and Lo (2009) combined FIS and talent analysis to introduce a new approach to technological strategy planning. By creating a knowledge base, this new approach distinguishes itself from other traditional tools of management decision-making [20]. Molavi and colleagues used multicriteria decision-making and FIS techniques to introduce a quantitative approach to prioritizing strategic enablers of organizational agility [21]. A comparison between FIS and ANFIS techniques in designing an effective information system shows that the results of ANFIS model are more effective due to their integration with neural networks, genetic algorithm, and/or other optimization techniques [22]. In a recent study, Mohanty and Parhi (2014) used ANFIS technique to solve the path planning problem of autonomous mobile robot [17].
One of the shortcomings of the BSC literature is that researchers do not consider the environmental factors in developing the strategy map. In this paper, the environmental factors affecting an organization were identified and their influence on the strategy map is captured. Moreover, the proposed strategy map is developed in the form of a scenariobased balanced scorecard, where the effects of environmental changes on the components of the strategy map are explicitly investigated. To this end, we design a "time-based strategy map" to take into account the time value of strategy map components. The influence of environmental factors on the strategy map components is investigated under different scenarios. Additionally, the degree of robustness of each component of the strategy map in relation to different scenarios is calculated. Subsequently, a method is proposed to calculate the degree of robustness of every component of the strategy map for the contingency of every scenario.

\section{Methodology}

Nowadays, it is necessary to use performance assessment models consistent with environmental changes due to enormous complexities and increasing changes of organizational environments. As one of the most prevalent models of organizational performance assessment, BSC can adequately adapt to environmental demands. The concept of robust strategy map is used in the present study in order to manage environmental uncertainties based on BSC model. Since past performance data are used to develop strategy maps in BSC model, possible futures and prospective futures are overlooked for the organization. By considering uncertainties of the organizational environment and creating a robust strategy map, one may increase organizational preparedness to deal with the uncertainties in the long run. The main steps taken in implementing the proposed methodology will be illustrated in the form of a conceptual model (see Figure 1). Subsequently, the developmental steps of the proposed model will be explained.

3.1. Developing Organizational Strategy Maps. Organizations tend to use strategy maps in the BSC model in order to create a common understanding of policies and strategies, in which the relationships among key components of the organization and its strategy are visually represented. Every strategy map should include four aspects entitled finance, customer, internal process, and learning \& growth. In each aspect, performance objectives should be defined and their causal relationships should be illustrated.

3.2. Partitioning the Strategy Map into Its Components. Once we show cause-effect relations on a strategy map from the lowest perspective (learning and growth) to the topmost perspective (financial), we will have a network of interrelated performance goals. All possible paths on the strategy map begin with one of the learning and growth goals; therefore, every goal on the learning and growth perspective can be considered as the starting point for a set of paths. In other words, the paths that begin with the lowest perspective and 


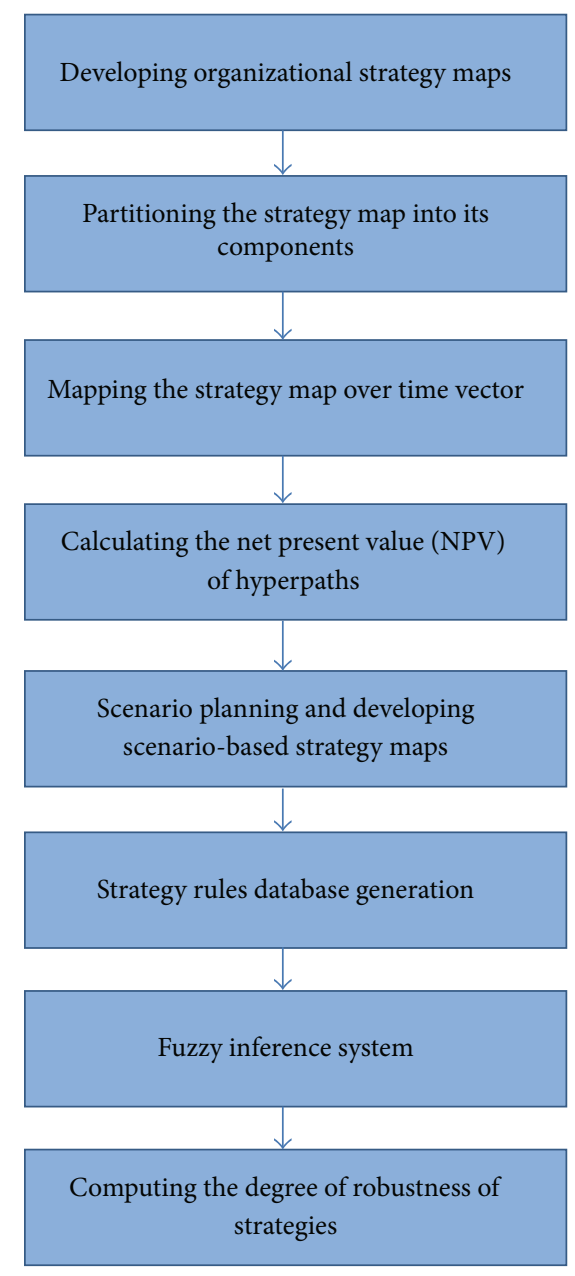

Figure 1: Proposed methodology.

work toward the topmost perspective on the strategy map can be mapped by considering a set of paths. We refer to these sets of paths as hyperpaths that constitute a complete partitioning of the strategy map. It, however, should be noted that hyperpaths overlap so that all of them end in an ultimate goal in the financial perspective. Every hyperpath is a context for strategic value creation in the organization that converts investment in the infrastructural goals to financial results over time. Figure 2 illustrates the portioning of the strategy map into hyperpaths.

3.3. Mapping the Strategy Map over Time Vector. Strategy maps indicate how BSC goals are interrelated and how they contribute to the maximization of the shareholders' profits as a goal in the financial perspective. Since financial goals of the organization in the financial perspective are realized with a time lag, the strategy maps were developed by modeling the time lag in the present study. As higher-order goals of the strategy map occur in future time periods, the cash flows (either cost or revenue) of the organization could be studied on the time vector. Figure 3 shows an example of the timebased strategy map.

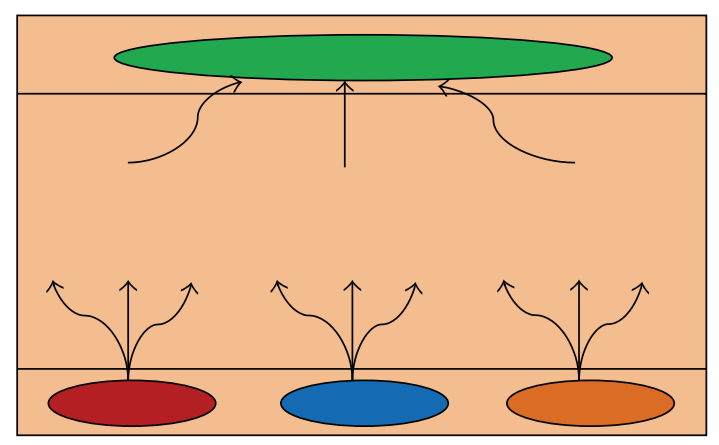

FIGURE 2: Partitioning the strategy map into hyperpaths.

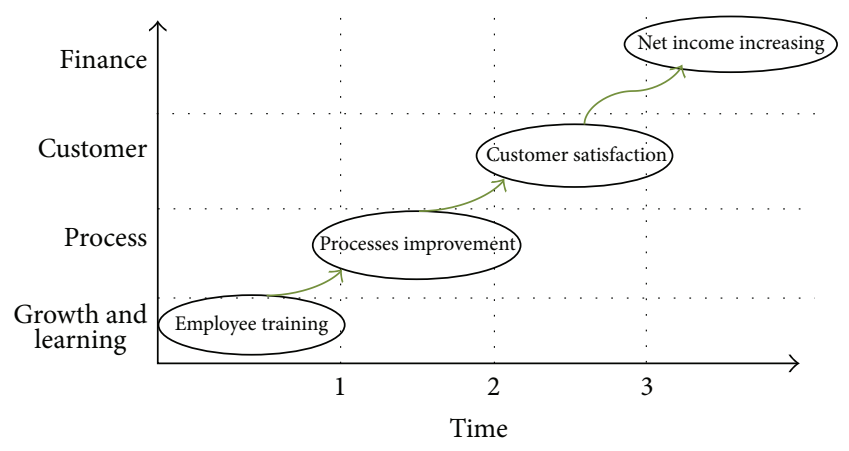

FIgURE 3: Time-based strategy map.

3.4. Calculating the Net Present Value (NPV) of Hyperpaths. As discussed earlier, an investment in a goal in the BSC learning and growth perspective would lead to an ultimate goal in the financial perspective with a time lag of a few periods. Focus on this time lag clarifies the real value of investment in a hyperpath in the strategy map at present and in future. NPV technique is used to adapt cash flow vector over time periods and transfer it to the present time. In this method, the cash flow (cost or revenue) is discounted at a rate of the day based on the time of occurrence (cost or revenue). In the NPV technique, all costs and revenues are discounted at an adequate rate based on the time of their occurrence. This is done via the following equation [23]:

$$
\operatorname{NPV}(i, N)=\sum_{t=1}^{N} \frac{\mathrm{FV}_{t}}{(1+i)^{t}}
$$

where $\mathrm{FV}_{t}$ is future value in period $t, N$ is the number of periods in the planning horizon and $i$ is annual interest rate.

Period 0 refers to the first year of investment.

Due to uncertainty in estimating future cash flows for every hyperpath, we use interval numbers rather than computing crisp NPV. As explained, every hyperpath can have certain choices. Every choice has a specific cash flow in order to reach higher-order goals; therefore, separate NPVs will be calculated for them. In the next section, we would see that a different NPV is obtained in every hyperpath for different choices. Figure 4 illustrates an example of time-based strategy map with the corresponding cash flow vector. 


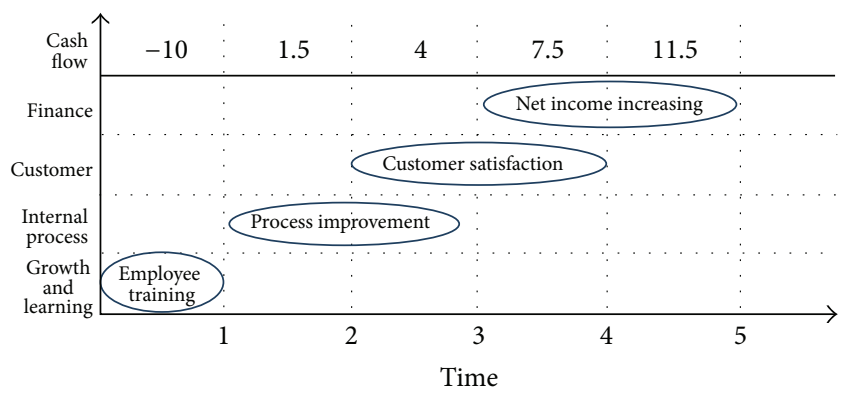

Figure 4: Time-based strategy map and corresponding cash flow over time.

\subsection{Scenario Planning and Developing Scenario-Based Strat-} egy Maps. As discussed in Section 2.2, organizations can benefit from the application of scenario analysis to creating the strategy map. The function of scenario analysis is to show how current decisions can affect future results. Scenario analysis can increase the effectiveness of strategy maps. Use of scenario analysis in creating strategy maps can add a contingency and predictive perspective to the standard model of strategy map design.

We employed the scenario analysis technique as proposed in Hanafizadeh et al.s paper in our methodology [24]. The Hanafizadeh et al. approach has this advantage that each scenario can be described in terms of environmental factors.

When used in the BSC framework, this kind of scenario analysis can assess the value of each organization's strategy in terms of different combination for the environmental factors. The organization strategy itself is a combination of different strategies for different hyperpaths.

3.6. Strategy Rules Database Generation. The values of critical success factors resulting from a strategy should be determined in order to calculate organizational performance for the implementation of a certain strategy. In facing a combination of various values of the stimuli, every strategy reflects certain values of critical success factors for the organization. Specific combinations of environmental stimuli and critical success factors resulting from a strategy implementation can be predicted with regard to the knowledge of experts and decision makers of the organization as well as past data of the organization. FIS can be used to simulate experts' knowledge in predicting future conditions for every strategy, and a knowledge base can be created based on it. Such a knowledge base is able to deduce and express the results of entering new combinations of stimuli values. Consequently, having entered the values of stimuli for every scenario, one can extract the output using the rules established in the knowledge base. In other words, critical success factors derived from strategy implementation is computed after entering the values of every scenario stimuli into such a system. Finally, the organizational performance is obtained for the environmental conditions after the strategy implementation. Experts use linguistic variables to express their idea and knowledge. For example, the value of every linguistic variable
TABLE 1: Hyperpaths strategies.

\begin{tabular}{ll}
\hline Hyperpaths & Hyperpaths strategies \\
A & $\begin{array}{l}\text { (1) Providing the organization experts with } \\
\text { specialty training } \\
\text { (2) Recruiting experts with a high educational } \\
\text { profile }\end{array}$ \\
\hline & (1) Creating a comprehensive, Web-based system \\
for all software used in the organization \\
(2) Using different software systems for different \\
organizational sections
\end{tabular}

can be determined using the set \{very small, small, medium, large, and very large\}.

3.7. Fuzzy Inference System (FIS). The FIS knowledge base comprises a set of rules extracted from every strategy. Every scenario is defined based on a certain combination of environmental stimuli and is finally expressed with fuzzy numbers. In this system, every scenario is entered into the knowledge base as a separate entry. Then the values of critical success factors are obtained based on FIS engine if-then rules. Finally, organizational performance is calculated via the sum total of their weights.

3.8. Computing the Degree of Robustness of Strategies. The higher the NPV of a strategy per occurrence of all strategies, the more attractive and robust it is. In fact, a strategy that has a better NPV in more contingent scenarios is more acceptable and more robust.

The output obtained from the implementation of FIS is used to compute the degree of the robustness of strategies. If the performance of strategy $i$ under scenario $j$ is shown as $R_{i j}$, the identical performance of two strategies in two different scenarios does not indicate their identical utility. Rather this figure makes sense when compared with the performance of other strategies in the same scenario. Thus, performance percentage instead of numerical value of performance is used in computing the degree of robustness. The percentage of performance well indicates how much of the whole performance in a scenario is produced by the strategy. Performance percentage is calculated as follows:

$$
\% R_{i j}=\frac{R_{i j}}{\sum_{i} R_{i j}} .
$$

The contingency of every scenario is another determining factor that should be addressed in computing the degree of robustness because the identical performance of a strategy in two scenarios with different contingencies means that the strategy will not have identical attractiveness and weight. In other words, the more contingent a scenario is, the higher the weight of strategy performance is. If $P_{j}$ represents the contingency of scenario $j$, the following equation is used to 
TABLE 2: Quantitative values of environmental factors under scenarios.

\begin{tabular}{lcccccc}
\hline \multirow{2}{*}{ Scenario } & \multicolumn{2}{c}{ Competitors performance } & \multicolumn{2}{c}{ Environmental factors } \\
& Linguistic & Quantitated & Linguistic & Quantitated & \multicolumn{2}{c}{ Alternative services } \\
& Weak & 2 & High & 7.5 & Low & Quantictic \\
\hline Optimistic & Mediocre & 6 & Mean & 4 & Mean & High \\
Realistic & Strong & 8.5 & Low & 1 & 5 & 9 \\
Pessimistic & & & & & High \\
\hline
\end{tabular}

compute the degree of robustness of every strategy for the occurrence of all scenarios [24]:

$$
\mathrm{DS}=\sum_{j} \% R_{i j} * P_{j} .
$$

\section{Case Study in a Post Company}

An Iranian post company was selected to implement the method proposed in the present study. Post services are considered as basic services such as water supply, power, and public education. The postal network conducted through those services is part of the social and economic infrastructure in the country. Considering the importance of and great changes in post services in the developed countries, the post company, selected as the case, suffers serious deficiencies and challenges. The percentage of employment in the post business and the ratio of the number of post offices to the population in Iran are considerably lower than the global average. The diversity, penetration rate, and speed of postal services are below the global standard. In addition to the above deficiencies, changes in post services are necessary due to organizational, legal, and technological factors. It is also necessary to increase productivity and review strategic programs and goals of the post due to the emergence of international competitors, offering postal services in a competitive market and increased role of technology in effective service offering. The above discussion would justify the selection of a post office to implement the proposed method. In this regard, a strategy map was drawn for the selected post company based on the BSC perspectives and cause-effect relations. Then the strategy map was partitioned into its components, hyperpaths, to carry out more exact analyses of financialeconomic flows. Every one of the three hyperpaths on the post company strategy map has different choices that are illustrated in Table 1. Every hyperpath will have two choices. Thus, there are eight different combinations $(2 \times 2 \times 2=8)$ for every scenario.

Like any other organization, post companies are affected by a set of external factors that exert an influence on intraorganizational performance. Table 2 illustrates the quantitative values of environmental factors under every scenario.

The effective stimuli and critical success factors need to be identified in order to determine the exact impact of every external factor on organizational performance. By studying the relationships between these two types of factors for every strategy, a knowledge base can be designed to display organizational performance under every strategy. Table 3 illustrates the strategy rules database designed for the post company.

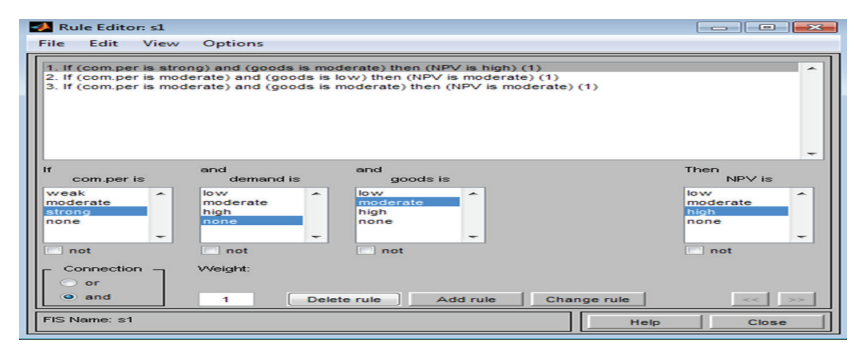

Figure 5: Knowledge base of $\mathrm{A}_{1} \mathrm{~B}_{1} \mathrm{C}_{1}$ strategy.

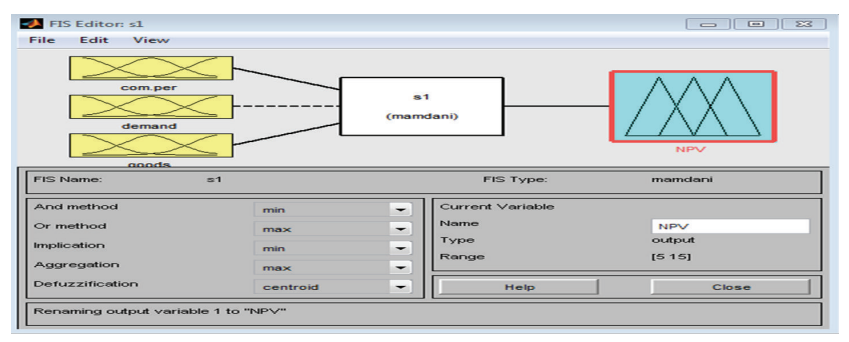

FIGURE 6: Inputs \& outputs in MATLAB.

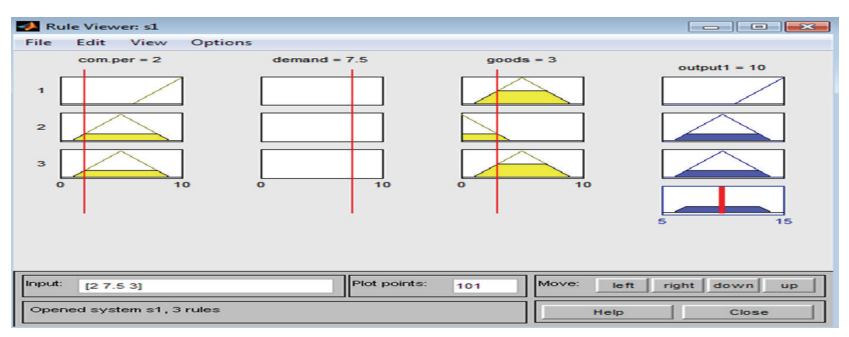

Figure 7: Output of $A_{1} B_{1} C_{1}$ strategy under optimistic scenario.

The data on external stimuli and intraorganizational critical success factors were inserted into the MATLAB software as inputs and outputs, respectively, to develop a fuzzy rules database. Figures 5-7 illustrate the process of the creation of the database in MATLAB software.

Now, the performance of the post company can be predicted based on the developed knowledge base and the occurrence of different environmental scenarios. To this end, every scenario should be defined in terms of environmental factors. The fuzzy inference engine, designed for every strategy, receives every scenario as an input and then displays the output (NPV) in the form of organizational performance in Table 4. 
TABLE 3: Knowledge base of strategies.

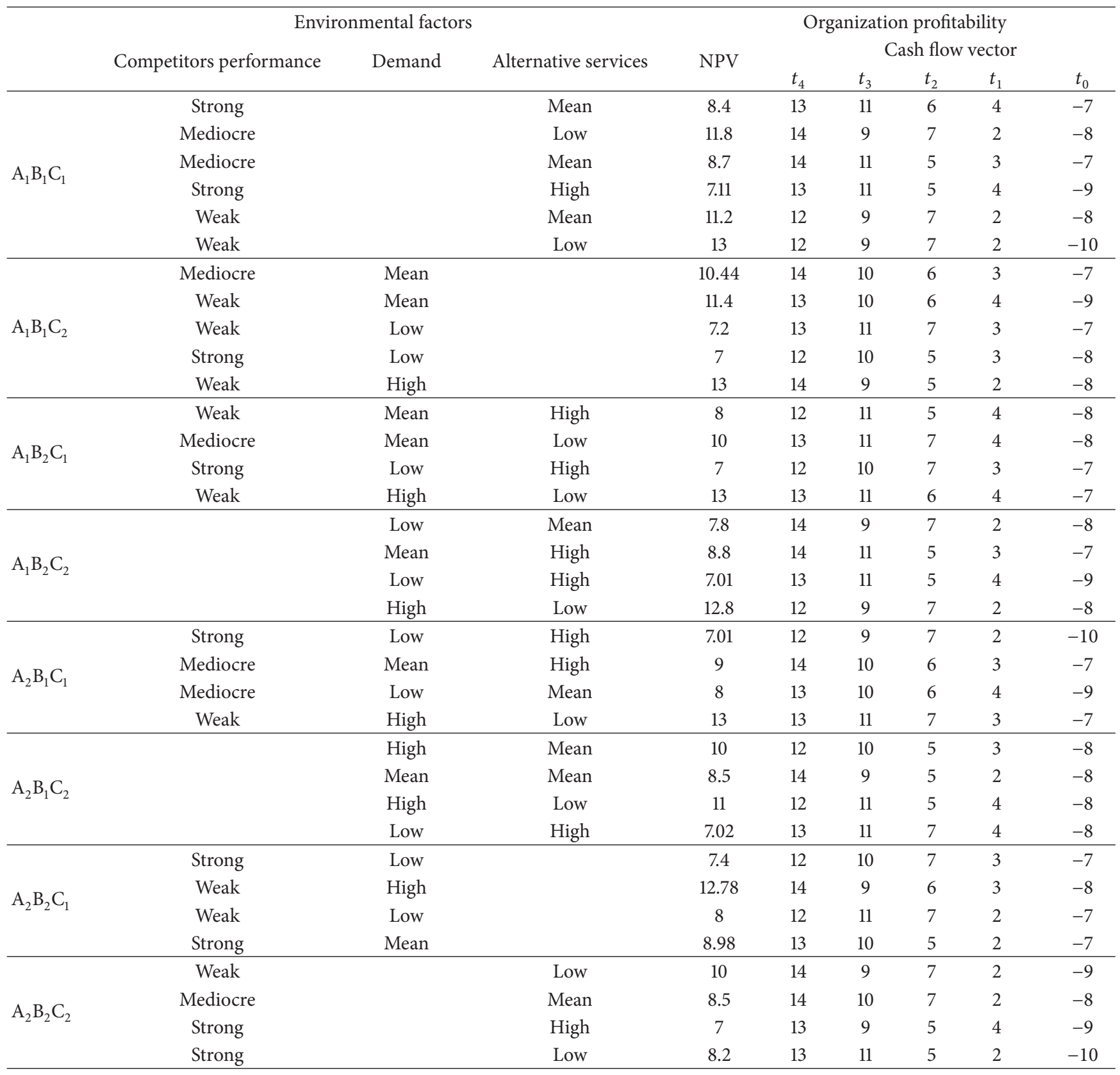

TABLE 4: Strategies' NPVs under three scenarios.

\begin{tabular}{|c|c|c|c|c|c|c|c|c|}
\hline \multirow{2}{*}{ Scenario } & \multicolumn{8}{|c|}{ Strategy } \\
\hline & $\mathrm{A}_{1} \mathrm{~B}_{1} \mathrm{C}_{1}$ & $\mathrm{~A}_{1} \mathrm{~B}_{1} \mathrm{C}_{2}$ & $\mathrm{~A}_{1} \mathrm{~B}_{2} \mathrm{C}_{1}$ & $\mathrm{~A}_{1} \mathrm{~B}_{2} \mathrm{C}_{2}$ & $\mathrm{~A}_{2} \mathrm{~B}_{1} \mathrm{C}_{1}$ & $\mathrm{~A}_{2} \mathrm{~B}_{1} \mathrm{C}_{2}$ & $\mathrm{~A}_{2} \mathrm{~B}_{2} \mathrm{C}_{1}$ & $\mathrm{~A}_{2} \mathrm{~B}_{2} \mathrm{C}_{2}$ \\
\hline Scenario 1 & 12.1 & 13.5 & 13.3 & 13.3 & 13.3 & 10 & 13.5 & 10 \\
\hline Scenario 2 & 7.92 & 10 & 10 & 10 & 10 & 6.37 & 6.74 & 10 \\
\hline Scenario 3 & 7.87 & 6.44 & 6.44 & 6.37 & 6.44 & 6.37 & 6.44 & 6.44 \\
\hline
\end{tabular}

For example, the number 12.1 is the output produced by the inference system based on strategy knowledge base $A_{1} B_{1} C_{1}$ under the first scenario with the input \{competitors' performance: strong, alternative goods: average\}. In order to compute the degree of robustness, we should first normalize the performance of every strategy, extracted from the system as NPV, under every individual scenario. Then, as shown in Table 5, the degree of robustness of every strategy for all potential scenarios was computed using (3). Finally, $A_{1} B_{2} C_{1}$ was selected as the more robust strategy. 
TABLE 5: Degree of robustness of strategies under three scenarios.

\begin{tabular}{lccccccccc}
\hline \multicolumn{2}{l}{ Scenarios } & \multicolumn{3}{c}{ Strategies } & & & \\
& & $\mathrm{A}_{1} \mathrm{~B}_{1} \mathrm{C}_{1}$ & $\mathrm{~A}_{1} \mathrm{~B}_{1} \mathrm{C}_{2}$ & $\mathrm{~A}_{1} \mathrm{~B}_{2} \mathrm{C}_{1}$ & $\mathrm{~A}_{1} \mathrm{~B}_{2} \mathrm{C}_{2}$ & $\mathrm{~A}_{2} \mathrm{~B}_{1} \mathrm{C}_{1}$ & $\mathrm{~A}_{2} \mathrm{~B}_{1} \mathrm{C}_{2}$ & $\mathrm{~A}_{2} \mathrm{~B}_{2} \mathrm{C}_{1}$ & $\mathrm{~A}_{2} \mathrm{~B}_{2} \mathrm{C}_{2}$ \\
\hline Scenario 1 & 0.20 & 0.12 & 0.14 & 0.13 & 0.13 & 0.13 & 0.10 & 0.14 & 0.10 \\
Scenario 2 & 0.65 & 0.11 & 0.14 & 0.15 & 0.14 & 0.14 & 0.09 & 0.09 & 0.14 \\
Scenario 3 & 0.15 & 0.15 & 0.12 & 0.12 & 0.12 & 0.12 & 0.12 & 0.12 & 0.12 \\
\multicolumn{2}{l}{ Degree of robustness } & 0.119 & 0.132 & 0.141 & 0.136 & 0.137 & 0.097 & 0.107 & 0.130 \\
\hline
\end{tabular}

\section{Conclusion}

Strategy maps lack the potential to deal with future changes in the organization as they have a retrospective approach. Thus, considering the rapid changes and increasing complexities of organizational environment, it is necessary to consider environmental uncertainties in in the models and outputs of organizational strategic management. Incorporating environmental uncertainties and organizational scenarios in redesigning strategy maps produces a new tool that is most compatible with real environmental conditions in an organization, hence the concept of robust strategy map under uncertain environmental conditions. In the present study, we first determined the choices related to every hyperpath of the strategy map. The combination of these choices constitutes the strategies of the organization. Subsequently, environmental stimuli affecting the organization were identified, and the most important factors were listed. Then fuzzy rules were defined, and the relationships between environmental stimuli and NPV of every strategy were described. A knowledge base was developed. By locating (interpolation and extrapolation) every scenario in the knowledge base, the NPV of every strategy was computed. Finally, the strategies were ranked in terms of their robustness based on the combination of contingency of every scenario and the generated NPV. In other words, the most robust strategy was created by considering all scenarios. Robust strategies have high adaptability in facing environmental changes and good dynamicity over time periods because environmental scenarios are updated continuously.

\section{Conflict of Interests}

The authors declare that there is no conflict of interests regarding the publication of this paper.

\section{References}

[1] R. S. Kaplan and D. P. Norton, Strategy Maps: Converting Intangible Assets into Tangible Outcomes, Harvard Business School Press, Boston, Mass, USA, 2004.

[2] H. Ahn, "Applying the balanced scorecard concept: an experience report," Long Range Planning, vol. 34, no. 4, pp. 441-461, 2001.

[3] H. Nørreklit, "The balance on the balanced scorecard-a critical analysis of some of its assumptions," Management Accounting Research, vol. 11, no. 1, pp. 65-88, 2000.

[4] R. Othman, "Enhancing the effectiveness of the balanced scorecard with scenario planning," International Journal of
Productivity and Performance Management, vol. 57, no. 3, pp. 259-266, 2008.

[5] E. Hiltunen, "Scenarios: process and outcome," Journal of Futures Studies, vol. 13, no. 3, pp. 151-152, 2009.

[6] F. Roubelat, "Scenario planning as a networking process," Technological Forecasting and Social Change, vol. 65, no. 1, pp. 99-112, 2000.

[7] A. Martelli, "Scenario building and scenario planning: state of the art and prospects of evolution," Futures Research Quarterly, vol. 17, pp. 57-70, 2001.

[8] P. Durance and M. Godet, "Scenario building: uses and abuses," Technological Forecasting and Social Change, vol. 77, no. 9, pp. 1488-1492, 2010.

[9] C. Bezold, "Lessons from using scenarios for strategic foresight," Technological Forecasting and Social Change, vol. 77, no. 9, pp. 1513-1518, 2010.

[10] R. Bradfield, G. Wright, G. Burt, G. Cairns, and K. van der Heijden, "The origins and evolution of scenario techniques in long range business planning," Futures, vol. 37, no. 8, pp. 795812, 2005.

[11] J. P. Martino, "A review of selected recent advances in technological forecasting," Technological Forecasting and Social Change, vol. 70, no. 8, pp. 719-733, 2003.

[12] M. E. Porter, Competitive Advantage, Free Press, New York, NY, USA, 1985.

[13] P. Schwartz, The Art of the Long View, Doubleday, New York, NY, USA, 1991.

[14] P. Schoemaker, "Scenario planning: a tool for strategic thinking," Sloan Management Review, vol. 36, no. 2, pp. 25-40, 1995.

[15] K. D. Miller and H. G. Waller, "Scenarios, real options and integrated risk management," Long Range Planning, vol. 36, no. 1, pp. 93-107, 2003.

[16] F. Buytendijk, T. Hatch, and P. Micheli, "Scenario-based strategy maps," Business Horizons, vol. 53, no. 4, pp. 335-347, 2010.

[17] P. K. Mohanty and D. R. Parhi, "Path planning strategy for mobile robot navigation using MANFIS controller," Advances in Intelligent Systems and Computing, vol. 247, pp. 353-361, 2014.

[18] N. Saberi and A. Rezaie, "Inference system application in quality analysis for underground water," Iran Environmental Engineering Journal, pp. 123-138, 2013.

[19] A. Moayer, P. A. Bahri, and A. Nooraii, "Adaptive neuro-fuzzy inference system for generating scenarios in business strategic planning," in Proceedings of the IEEE International Conference on Systems, Man and Cybernetics (ISIC '07), pp. 109-114, Montreal, Canada, October 2007.

[20] W.-D. Yu and S.-S. Lo, "Patent analysis-based fuzzy inference system for technological strategy planning," Automation in Construction, vol. 18, no. 6, pp. 770-776, 2009.

[21] B. Molavi, M. Esmaeilian, and R. Ansari, "Proposing a new approach for prioritization of organizational agility strategies 
using FTOPSIS and fuzzy inference system," IRAN Industrial Management Journal, vol. 5, no. 1, pp. 123-138, 2014.

[22] B. P. Kaur and H. Aggrarwal, "An optimization of a planning information system using fuzzy inference system and adaptive neuro-fuzzy inference system," WSEAS Transactions on Information Science and Applications, vol. 10, no. 8, pp. 249-260, 2013.

[23] M. Y. Khan, Theory \& Problems in Financial Management, McGraw Hill Higher Education, 1993.

[24] P. Hanafizadeh, M. Rezaei, and A. Ghafouri, "Defining strategic processes in investment companies: an exploration study in Iranian investment companies," Business Process Management Journal, vol. 15, no. 1, pp. 20-33, 2009. 


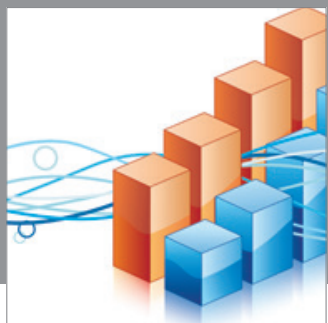

Advances in

Operations Research

mansans

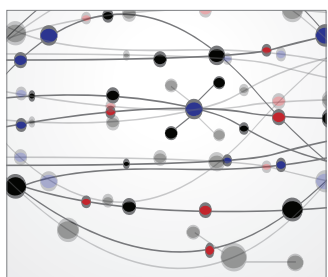

The Scientific World Journal
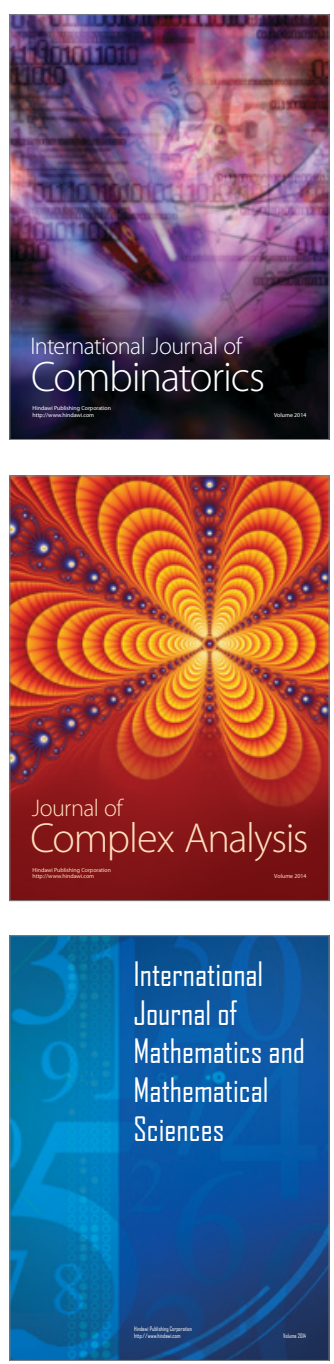
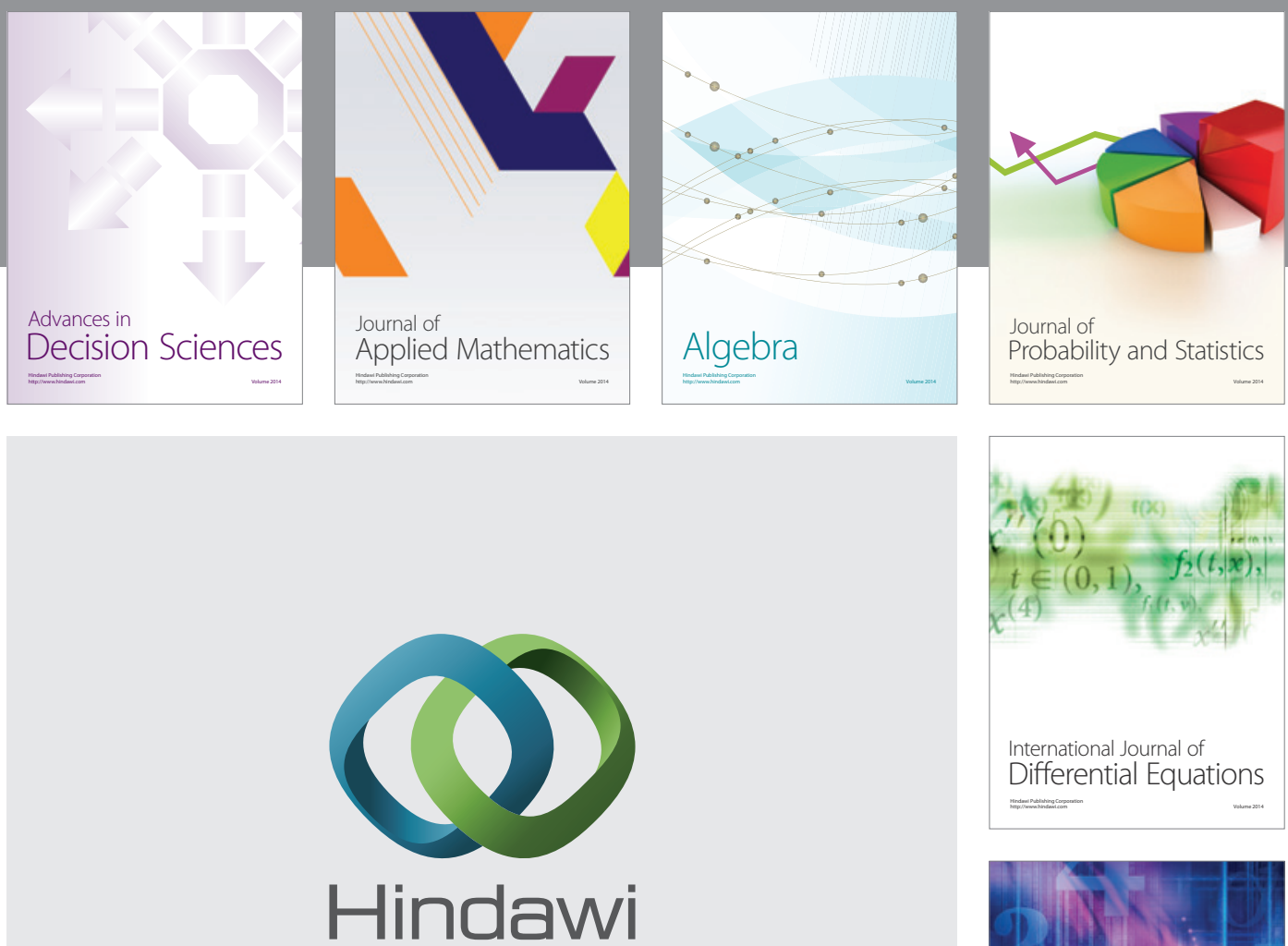

Submit your manuscripts at http://www.hindawi.com
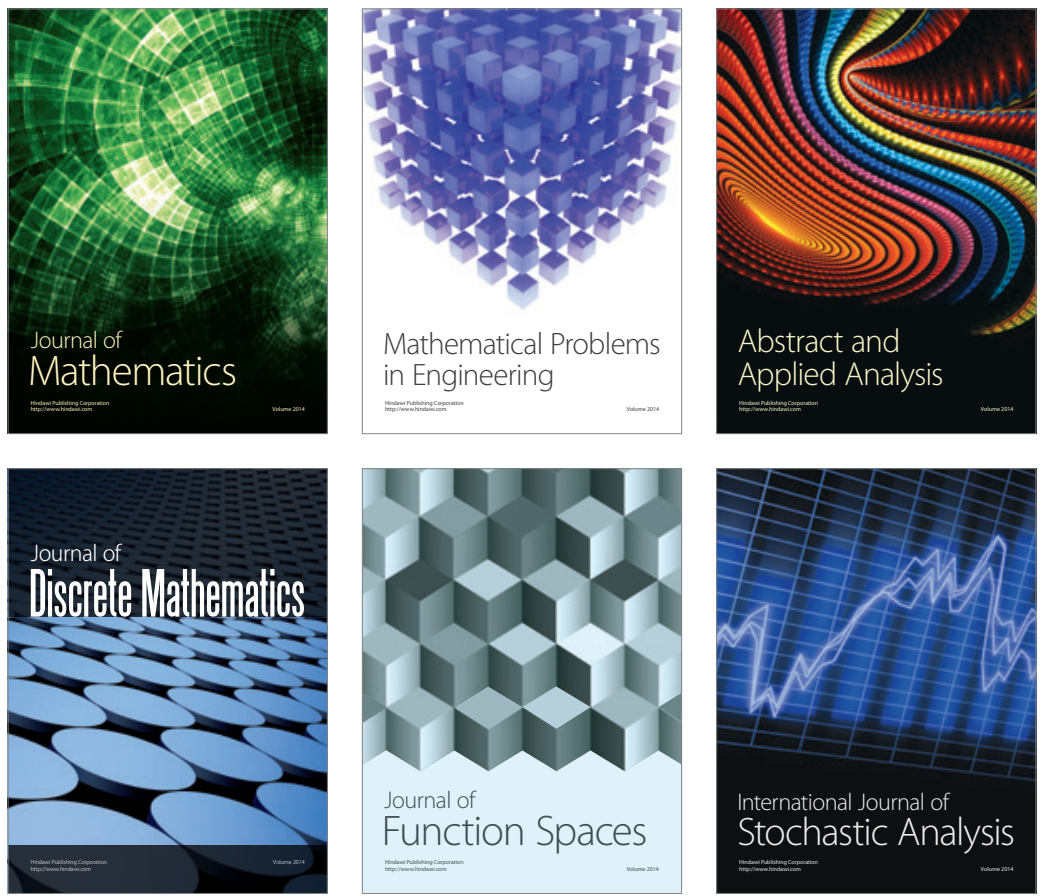

Journal of

Function Spaces

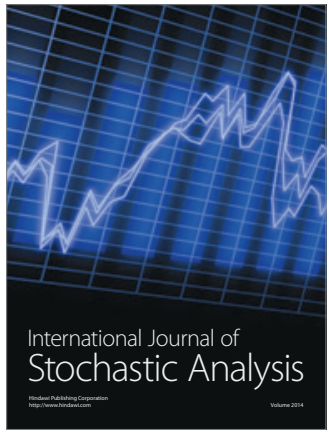

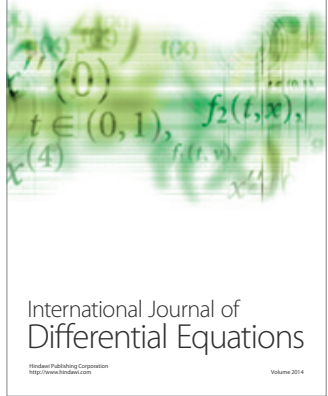
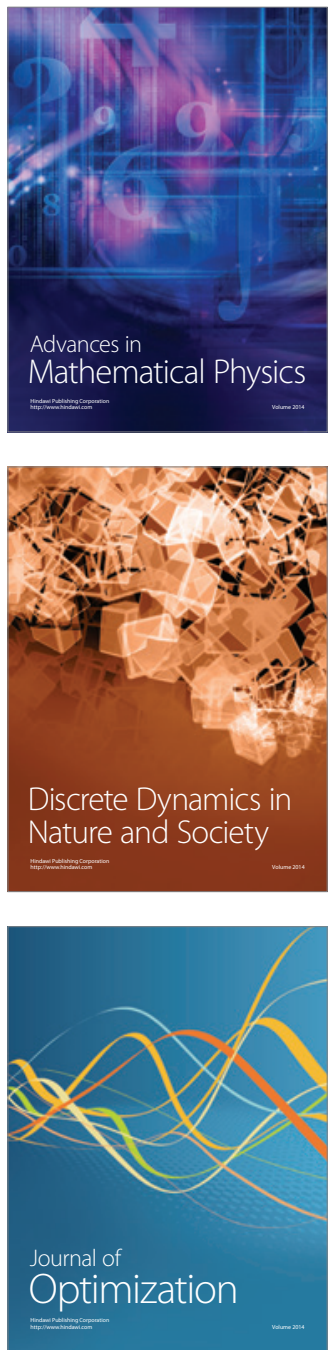